\title{
CUTANEOUS XANTHOGRANULOMA OF THE FACE - AN UNCOMMON CLINICAL DIAGNOSIS AND CHALLENGING RECONSTRUCTION
}

\author{
Y. Yordanov' ${ }^{1}$ A. Shef ${ }^{1}$, O. Bogdanova², I. Hristov² \\ ${ }^{1}$ ASD Consult - Sofia, Bulgaria \\ 2Unit of Pathology, 5th MHAT - Sofia, Bulgaria
}

\begin{abstract}
Cutaneous xanthogranuloma is a rare benign tumor and both adults and children could be affected. Head and neck area of the human body is the most commonly affected one which often poses a serious reconstructive challenge for the plastic surgeon who is in charge of removing the lesion. We report on a clinical case of an adult female patient who presented with cutaneous xanthogranuloma of the upper lip, involving the subnasal area. Both diagnosis and surgical treatment were difficult, considering the clinical behavior and location of the tumor. An innovative surgical approach going out of the dogmas of plastic surgery was applied and an excellent result was achieved.
\end{abstract}

Key words: cutaneous xanthogranuloma, upper lip repair, Dufourmentel flap

Corresponding author: Yordan P. Yordanov MD, PhD, FEBOPRAS, ASD Consult, 38 Ivan Evst. Geshov Blvd., 1612 Sofia, Bulgaria, e-mail: yordanov_vma@abv.bg

\section{INTRODUCTION}

$\longrightarrow$ utaneous xanthogranuloma is a benign tumor, which is a type of the non-Langerhans cell group of proliferative disorders of mononuclear phagocytes [1, 2]. Since it has been first described by Adamson in 1905 [3], its etiology still remains unclear. However, it has been hypothesized that xanthogranulomas are more or less a result of a reactive process $[1,4]$.

From the other hand, the upper lip and subnasal unit of the face are among the most challenging areas for reconstruction in terms of anatomy, function and aesthetics. The classical techniques for repair include advancement flaps, lip-switch flaps, and skin grafts, which often leads to significant disfigurement and aesthetic concerns among the patients $[5,6]$.

We report on a clinical case of a female patient who presented with a cutaneous xanthogranuloma of the upper lip, involving the subnasal area. After the initial surgical ablation, a one-stage reconstruction of the residual defect was performed by using a Dufourmentel pivotal flap instead of the classical techniques.

\section{CASE REPORT}

A 50-year-old woman presented with a 5-month history of a growing painless facial lesion. Initially it started like a small white papule but after an intention to squeeze it, the papule rapidly progressed into a rounded lesion. Clinical examination revealed a $1.1 \mathrm{~cm}$ heterogeneously brown-yellowish-pigmented dome-shaped lesion, located on the skin of the left medial element of the upper lip distally to the left nostril (Fig. 1A). It caused discomfort and subjective feeling of nostril obstruction to the patient. The cutaneous margins were with slight inflammation at the base of the lesion but still mobile, and showed no regional lymphadenopathy. Dermoscopy revealed 
branched linear vessels at the periphery of the lesion and paucity of yellow globules.

Under local anesthesia with lidocaine and epinephrine 1:100 000 the lesion was excised with a 2-mm margin of normal tissue. Dufourmentel local flap was meticulously harvested from the superior portion of the ipsilateral nasolabial fold in order to repair the post-excisional defect (Fig. 1B). Histopathological examination revealed a dermis with chronic granulomatous inflammatory infiltrate with a mixture of foamy histiocytes and Touton giant cells, which are pathognomonic hallmark of cutaneous xanthogranuloma (Fig. 1C). Thus, the histopathological diagnosis of adult cutaneous xanthogranuloma was established. Follow-up period was uneventful and good anatomic, functional and aesthetic outcome was observed at the 12th day and 6 weeks postoperatively (Fig. 1D).

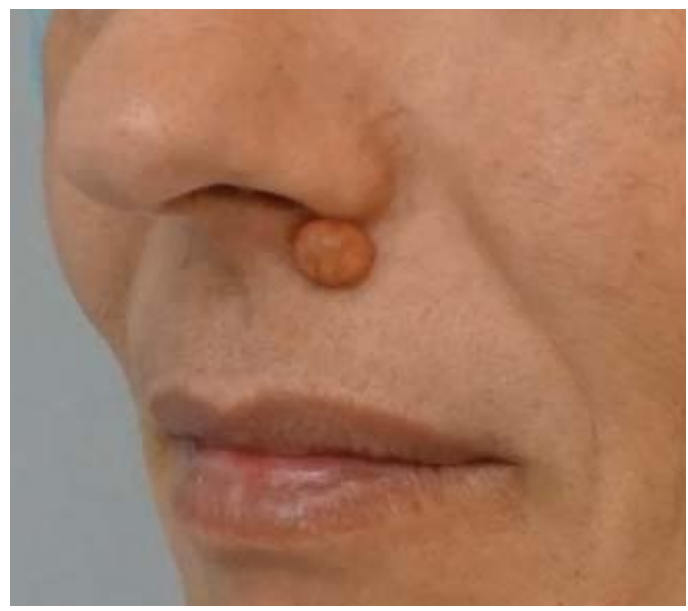

A. Preoperative view

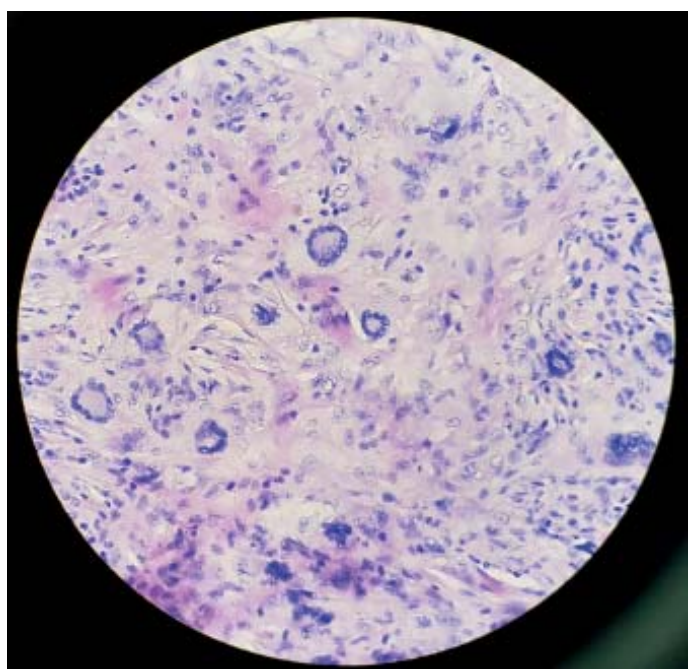

C. Hematoxylin and eosin staining high-power magnification (40x): Tuton giant cells are seen
There was no traction, nor deformation of the operated area and the surrounding structures: upper lip and vermilion border, the nostril and the nasolabial fold.

\section{DISCUSSION}

Xanthogranulomas are the most common form of non-Langerhans cell histiocytosis. They are rare in the daily practice and the right incidence is unknown [1]. Both adult and childhood forms have been described $[1,7,8]$ and the classic form - the dome-shaped xanthogranuloma is reported to be not larger than $0.5 \mathrm{~cm}$ [9]. In our case the clinical diagnosis was difficult and quite unsure because of the appearance of the lesion demonstrating some concerning features like untypical size (double the classical form), fast growth, uneven color changing

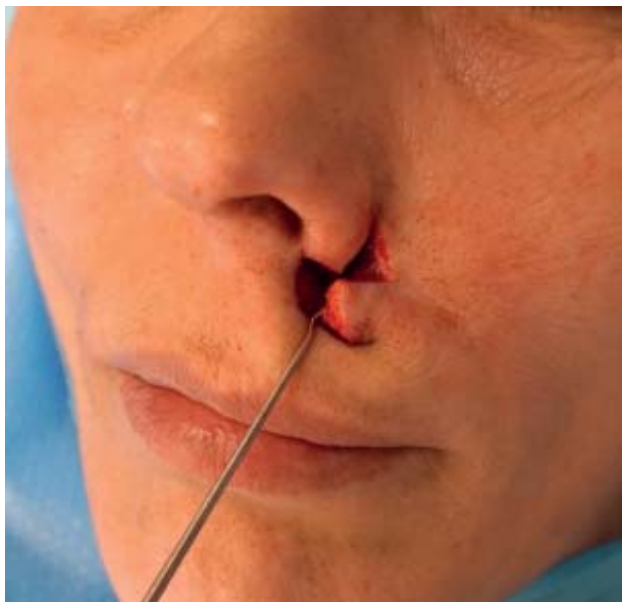

B. Harvested Dufourmentel flap prior to its insertion in place

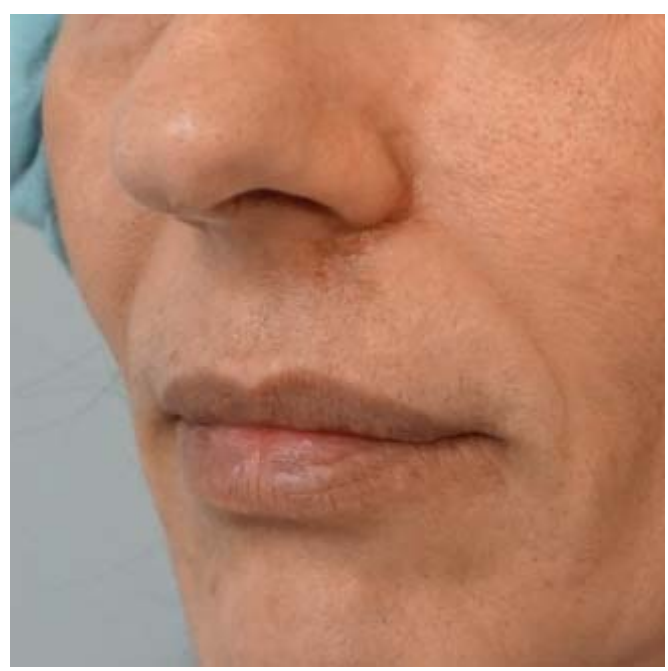

D . Postoperative outcome at 6 weeks

Fig. 1. The clinical case 
over the last three months and an inflammation at the base. Dermoscopic features, in turn, were not clear enough for a malignancy to be definitely excluded. That's why an excision with $2 \mathrm{~mm}$ border was planned and executed. In such a gentle area there are plenty of neighbor structures which have to be preserved. Thus, choosing the right reconstructive technique was the most difficult issue at the time of repair. For upper lip defects larger than 1-1.5 cm the advancement flaps are suggested to be the best choice especially when the vermilion border is affected [5,6]. Nevertheless, on the base of our experience in facial plastic surgery we decided to use a rhomboid flap with the modification of Dufourmentel - a surgical approach which the senior author has previously described [10]. Even slightly more complicated to design, in rhomboid defects with angles of less than $60^{\circ}$ (Fig. 2), the Dufourmentel flap could be planned a narrower than the classical Limberg rhomboid flap which makes donor site closure much easier with less disfigurement and elongation of the upper lip [10-12]. Thus, by making a good preoperative planning and applying a meticulous surgical technique we succeed to harvest the flap from the proximal nasolabial fold with no distortion of this important facial landmark.

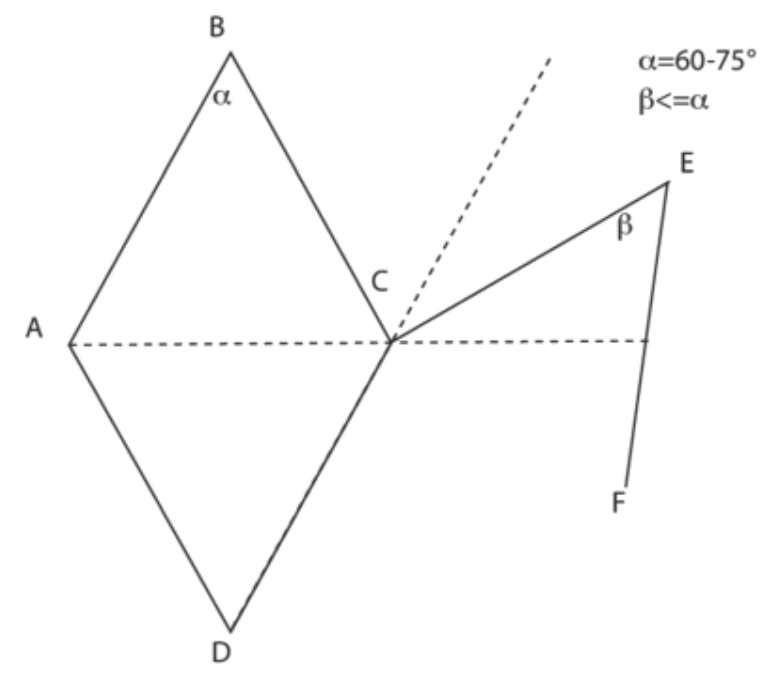

Fig. 2. Dufourmentel flap classical design. $\alpha$ - angle is greater than $60 \mathrm{o}$ and usually ranges between $60-750$

\section{CONCLUSION}

Adult cutaneous xanthogranuloma is a rear diagnosis in the clinical practice but should be always taken into consideration and the pathology study is the key to the right diagnosis. When gentle areas of the face are affected an appropriate preoperative planning and surgical technique have to be applied. This case report shows once again that the facial plastic surgery is a unique mix of science, practice and art. In order to achieve good results preserving form, function and aesthetics, the plastic surgeon has to be aware of all the existing techniques without being dogmatic in his or her particular choice.

Disclosure Summary: The authors have nothing to disclose.

\section{REFERENCES}

1. Ladha MA, Haber RM. Giant Juvenile Xanthogranuloma: Case Report, Literature Review, and Algorithm for Classification. J Cutan Med Surg. 2018;22(5):488-494.

2. Mun JH, Ohn J, Kim KH. Dermoscopy of giant juvenile xanthogranuloma. J Am Acad Dermatol. 2017;76(2)(suppl 1):S76-S78.

3. Adamson $\mathrm{H}$. Society intelligence: the Dermatologic Society of London. Br J Dermatol. 1905;17:222.

4. Herbst AM, Laude TA. Juvenile xanthogranuloma: further evidence of a reactive etiology. Pediatr Dermatol. 1999;16(2):164.

5. Luce EA. Upper lip reconstruction. Plast Reconstr Surg. 2017; 140:999-1007.

6. Salibian AA, Zide BM. Elegance in Upper Lip Reconstruction. Plast Reconstr Surg 2019;143(2):572-82. Discussion: 585-588.

7. Tan LC, Tan KB, Aw CW. Unusual presentation of adult xanthogranuloma: a case report. Singapore Med J. 2014;55(2):e25-e27.

8. Nayak S, Acharjya B, Devi B, Patra MK. Multiple xanthogranulomas in an adult. Indian J Dermatol Venereol Leprol. 2008;74:67-68.

9. Clayton TH, Mitra A, Holder J, Clark SM. Congenital plaque on the chest. Diagnosis: solitary giant congenital juvenile xanthogranuloma. Clin Exp Dermatol. 2007;32(5):613-614.

10. Yordanov YP. Dufourmentel Flap as an Aesthetic and Anatomic Refinement Tool in Upper Lip Repair. J Craniofac Surg. 2019 Sep 27. doi: 10.1097/SCS.0000000000005954. [Epub ahead of print].

11. Fee WE Jr, Gunter JP, Carder HM. Rhomboid flap principles and common variations. Laryngoscope. 1976;86(11):1706-11.

12. Park SS, Little S. Rhombic flaps. In: Baker SR, ed. Local Flaps in Facial Reconstruction. 3rd ed. Philadelphia: Saunders Elsevier Inc.; 2014: 210-30.

Received and accepted: Octover, 2019 